\title{
Dark Skies Rangers - Fighting light pollution and simulating dark skies
}

\author{
Rosa Doran $^{1}$, Nelson Correia ${ }^{1,2}$, Rita Guerra $^{1}$ and Ana Costa ${ }^{1}$ \\ ${ }^{1}$ NUCLIO - Núcleo Interactivo de Astronomia \\ Largo dos Topázios, 48, 3 Frt, 2785-817 S. D. Rana, Portugal \\ email: geral@nuclio.pt \\ ${ }^{2}$ Escola Secundária Maria Lamas \\ Rua 25 de Abril, 2350-786 Torres Novas, Portugal
}

\begin{abstract}
Dark Skies Rangers is an awareness program aimed at students of all ages to stimulate them to make an audit of light pollution in their school/district. The young light pollution fighters evaluate the level of light pollution, how much energy is being wasted, and produce a report to be delivered to the local authorities. They are also advised to promote a light pollution awareness campaign to the local community targeting not only the dark skies but also other implications such as effects in our health, to the flora and fauna, etc.
\end{abstract}

Keywords. miscellaneous, sociology of astronomy, data analysis, surveys.

A common debate in astronomy and space science gatherings is the fact that light pollution is growing too fast and our efforts to fight it are far from being enough. In order to efficiently fight this we need to recruit an army of literate soldiers, with a good understanding of our disappearing skies and the consequences it may bring. Recruiting schools to help astronomers in this enterprise might be a quick and effective solution. It is a win-win situation where teachers can address topics of the curricula using modern trends for science education and students may gain a deeper knowledge about our symbiosis with nature.

Dark Skies Rangers (DSR) is a joint collaboration between the National Optical Astronomy Observatory of the USA (NOAO) and the Galileo Teacher Training Program (GTTP). A very good repository of materials was created and is available in www.darkskiesawareness.org/DarkSkiesRangers. In Portugal a pilot effort was implemented in the municipalities of Cascais and Torres Novas to test the adaptability of the tools and resources in classroom, the receptivity of the communities and impact in the school. All the information of the efforts in Portugal can be found in dsr.nuclio.pt.

In Cascais the program started with 50 students analysing the light pollution in the streets surrounding their schools. During the school year of 2012/2013 ten more schools will integrate the program and the objective is to have a good map of the light pollution in the major areas of town. In Torres Novas the program was adopted by 93 students and 10 teachers in a cooperative effort. Students from 7 th to 12 th grade were involved in a wide range of activities. This project received an "Science in School" award from the Portuguese Foundation Ildio Pinho.

In the school year of 2012/2013 the program will be included in the Eco-Schools program and will be publicised in 1500 Portuguese eco-schools. The objective is to build a sustainable community of light pollution rangers. This program is using the IBSE model to share the good practices with the participants as part of the pilot efforts of the European Commission's funded project "Discover the Cosmos", under the scope of the FP7. 